\title{
Corporate Social Responsibility: Universities in the Kingdom of Bahrain
}

\author{
Afaf Ahmed Tawash ${ }^{1}$, Abdulmonem M. Al-Shirawi ${ }^{2} \&$ Adel M. Sarea ${ }^{3}$ \\ ${ }^{1}$ MBA Program, College of Business and Finance, Ahlia University, Kingdom of Bahrain \\ ${ }^{2}$ Department of Management \& Marketing, College of Business and Finance, Ahlia University, Kingdom of Bahrain \\ ${ }^{3}$ Department of Accounting \& Economics, College of Business and Finance, Ahlia University, Kingdom of Bahrain \\ Correspondence: Dr Abdulmonem M. Al-Shirawi, Department of Management \& Marketing, College of Business \\ and Finance, Ahlia University-Kingdom of Bahrain.
}

Received: June 23, 2019

doi:10.5430/rwe.v10n3p26
Accepted: August 4, 2019

Online Published: August 12, 2019

URL: https://doi.org/10.5430/rwe.v10n3p26

\begin{abstract}
Corporate Social Responsibility (CSR) has become very vital for any corporation as many voices demand that entities must be accountable for business decisions and actions. Since universities are vital entities in the society as they provide higher education to the human factor, they have a huge role that compels them to adhere to CSR and to make it a part of their strategic planning. The study is about measuring the awareness of CSR in the management of universities in the Kingdom of Bahrain. The study used a descriptive survey method to analyze the relationship between Communication, CSR activities and Management's transparency with the level of awareness of CSR. The respondents of the study are the top and middle level managers of universities where the primary tool in gathering data was a structured questionnaire. Secondary sources were utilized as well, such as: books, articles, unpublished thesis and other printed resources related to the study that were used to support and strengthen the findings of the study. The main finding is, there is a significant relationship between CSR activities and communication with awareness of CSR.
\end{abstract}

Keywords: corporate social responsibility, CSR activities, communication, awareness, transparency

\section{Introduction}

Corporate Social Responsibility (CSR) refers to "the business practices that firms take on as an effort to improve societal well-being" (Mishra \& Modi, 2016). Recently, this topic has become very vital for any corporation as many voices demand that entities must be accountable for business decisions and actions. CSR can take many forms like ethics, awareness of corporate effect on the environment, community engagement, etc. Nowadays, CSR is being integrated in companies' strategic planning and throughout its goals and objectives.

"Universities are vital entities in the society as they provide higher education to the human factor. Education produces basic properties and services for meeting the vital needs of a nation like health, security, education, defense, communication and cultural development" (Topal et al, 2005). Therefore, universities have a huge role that compels them to adhere to CSR and to make it a part of their strategic planning.

The chairman of Bahrain CSR Society stated that "many companies give close attention on how they are perceived by their customers and the general public. It was noted that the companies that promote their CSR programmes are perceived more favorably than those that do not have highly visible activities on CSR. When customers see that a company has a goal and a vision that goes beyond profits definitely provides a warmer image and will ultimately make customers engage with them more" (Bahraincsrsociety.com, 2016).

There are very few studies and researches covering the topic of CSR in the Management of universities in the Kingdom of Bahrain that measures the level of awareness of CSR. Similar studies have been conducted in many countries, for example: Spain (Jorge, M.L. and Peña, 2014), Polland, Austallia (Jonson et al, 2015), Uruguay (Vázquez et al, 2013) and Malaysia (Othman \& Othman, 2012).

\section{Research Questions}

The study developed various hypotheses that investigate awareness of CSR in the Management of universities in the Kingdom of Bahrain. Figure 1 below presents the proposed model and factors affecting the awareness of CSR 
The hypotheses of the current study are:

$\mathrm{H}_{0 \mathrm{a}}$ : Management Communication as a measure of CSR has no significant impact on managers' CSR awareness

$\mathrm{H}_{0 \mathrm{~b}}$ : CSR activities as a measure of CSR has no significant impact on managers' CSR awareness

$\mathrm{H}_{0 \mathrm{c}}$ : Level of Management's Transparency as a measure of CSR has no significant impact on managers' CSR awareness

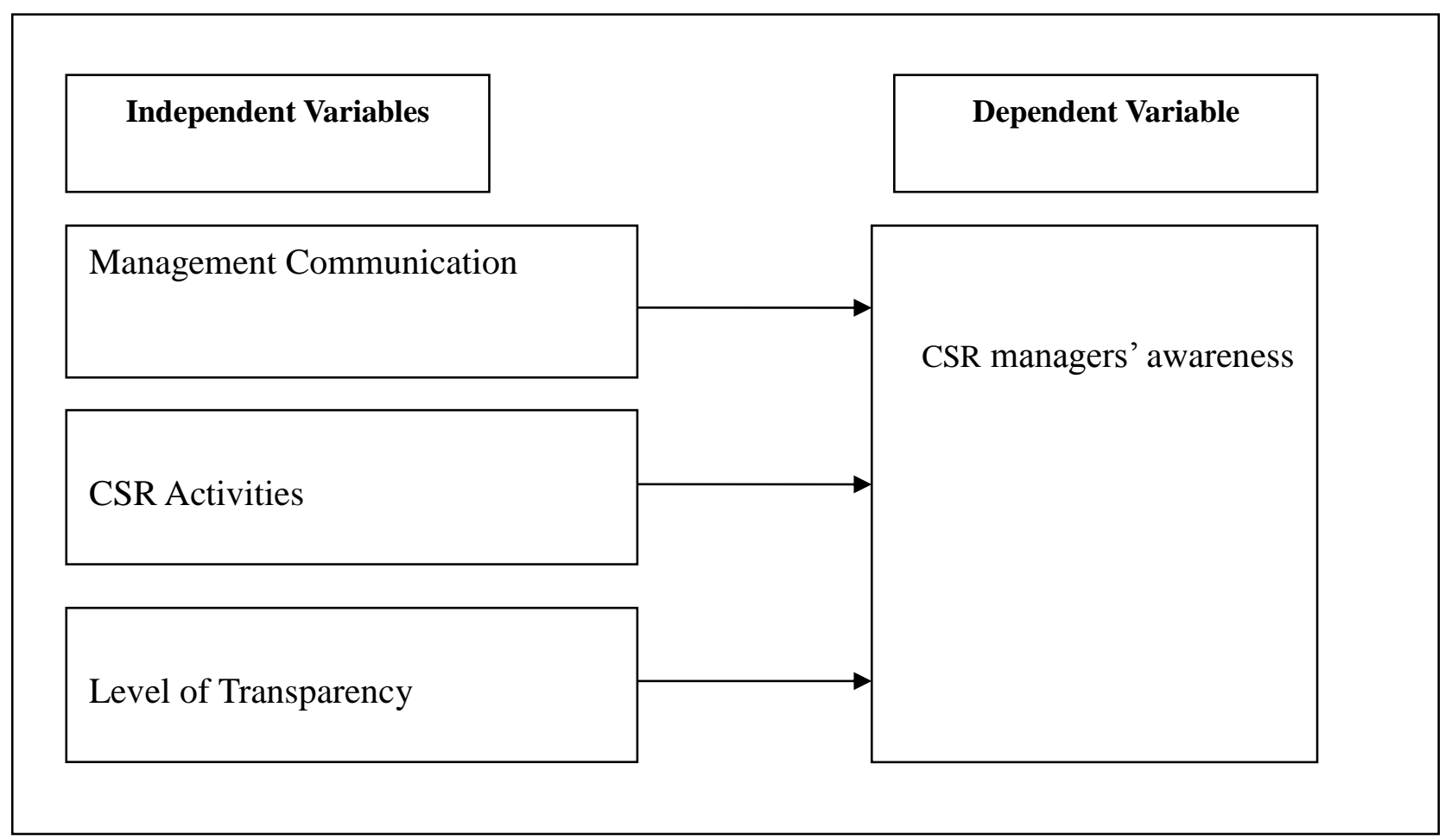

Figure 1. Research conceptual framework - Developed by authors

\section{Litreture Review}

Othman and Othman (2012) in their study titled "Higher Education institutions and social performance: evidence from public and private universities" which compared one private university to a public university in Malaysia concluded that the two universities have different attitudes when it comes to the implementation of CSR. "The public university focuses on maintaining its image and status and aims to change slowly without compromising its core identity and reason for its existence which is providing education to students first, and then prove their commitment to the society. The private university on the other hand chose to apply a different strategy and employs CSR to be a vital part of its response to the market demands. It used CSR as a marketing strategy to show its involvement to the community in order to recruit more students. Although both findings are interesting, it revealed that social responsibility was important to both universities each in their own way".

Mackey et al (2007) They argued that "firms should invest in socially responsible behavior, even if it may lead to the reduction of the present value of a firm's cash flows. They provided an explanation of when these kinds of investments can be done claiming that some investors may have goals other than wealth maximization. If this theory is true, then the only way to make profit is if the demand for socially responsible activity generated by these investors is greater than the supply CSR opportunities, then such investments can create economic value for a firm. The opposite is true also where if supply is higher than the demand, the investing in CSR will certainly reduce the market value of a firm". In another study, Giroud \& Mueller (2011) indicated that firms in competitive industries benefit less from good governance, while other firms in non-competitive industries benefit relatively more. 
Nejati et al (2011) studied the websites of the top 10 universities (private and public) in the world to shed the light on whether these institutions are committed to apply CSR and to what extent do they implement it. They reached the conclusion that "all the sampled top 10 world leading universities are engaged in social responsibility and sustainability activates and made sure to reflect that in their websites. The researchers believe that this finding provides best practices to less recognized universities to have more focus on implementing CSR activities but the CSR plans should consider the cultural differences of nations".

\section{Research Methodology}

Since the data can be collected and presented in a numerical form to explain the phenomena, the researcher chose the quantitative method. Ideally, the research will employ a Likert scale in its questionnaire. It is an ideal approach to measure people's attitudes on a particular topic where respondents specify their level of agreement or disagreement on particular statement over a symmetric scale.

Population: The research will be conducted on top to middle level managers in public and private universities of Bahrain. The target population includes but not limited to: Presidents, vice presidents, Administrators in the following universities: University of Bahrain, Ahlia University, AMA International University, Applied Science University, Royal Women University, Arab Open University, Kingdom University, University College of Bahrain, RCSI, and Talal Abu Ghazala University College. The population size of 100 was determined through the organizational charts published in the mentioned universities' website.

Data collection: This research was able to have a sample size of eighty eight (88) respondents only. This research will employ convenient sampling in which any manager from the targeted population is willing to participate with his/her input will be considered. And since the target population is Top to middle level managers in public and private universities of Bahrain, the researcher expects them to be busy as the nature of their job implies, so the use of convenient sampling is most appropriate. Moreover, this research approach guarantees the utmost accuracy in gathering a dependable and reliable data

Pilot Study: the reliability and validity of the study has been assessed and a pilot study has been performed prior to the official study by distributing a sample of 30 questionnaires on a convenient sample of participants. Cronbach's alpha test has been employed to estimate reliability.

Data Analysis: the Statistical Package for Social Science (SPSS) version 18.0 has been used for statistical analysis of the data collected.

\section{Result and Discussion}

The following tests are conducted on sample ( 88 respondents) to obtain the results of the study for analysis. The first section presents the results of the Reliability test of the questionnaire items while the second section presents the Normality (Skewness and Kurtosis) of the entire sample size. The third section employs the research method which is correlation while the fourth section presents the results of the regression analysis of the study.

\subsection{Correlation}

Table 1. Correlation test results

\begin{tabular}{lll}
\hline Independent Variable & Correlation & Interpretation \\
\hline Communication & $.302^{* *}$ & $\begin{array}{l}\text { There is a positive correlation and is Statistically } \\
\text { Highly significant }\end{array}$ \\
\hline CSR activities & $.519^{* *}$ & $\begin{array}{l}\text { There is a positive correlation and is Statistically } \\
\text { Highly significant }\end{array}$ \\
\hline Management transparency & $.392^{* *}$ & $\begin{array}{l}\text { There is a positive correlation and is Statistically } \\
\text { Highly significant }\end{array}$ \\
\hline
\end{tabular}

**. Correlation is significant at the 0.01 level (2-tailed).

Based on Table 1, we can see that there is a positive correlation between Awareness and communication which suggests that the relationship between them exists because of the highly significant statistical value of 0.302 which is higher than 0.01 . 
While for the second variable, which is CSR activities, we can tell that there is a positive correlation and is Statistically Highly significant at a value of 0.519 .

For the third independent variable, Transparency, it was found that there is also a positive correlation between it and the dependent variable which means that it is Statistically Highly significant with a value of 0.392 .

The correlation test results shows clearly that communication, CSR activities and Transparency are indeed factors that have a relationship with the level of awareness of CSR in the management of universities.

Linear Regression: This kind of statistical analysis method used to measure the level of awareness of the concept of CSR in the management of universities. The linear regression equation is as follows:

$$
\mathrm{Y}=\beta_{0}+\beta_{1} * \mathrm{X}_{1}+\beta_{2} * \mathrm{X}_{2}+\beta_{3} * \mathrm{X}_{3}+\varepsilon
$$

Where:

Table 2. Regression Model legend

\begin{tabular}{ll}
\hline $\mathrm{Y}$ & CSR Awareness \\
\hline$\beta_{0}$ & intercept (constant) \\
\hline$\beta_{1}$ & Slope 1 (regression coefficient) of Communication \\
\hline$\beta_{2}$ & Slope 2 (regression coefficient) of CSR activities \\
\hline$\beta_{3}$ & slope 3 (regression coefficient) of Transparency \\
\hline $\mathrm{X}_{1}$ & Independent variable 1: Communication \\
\hline $\mathrm{X}_{2}$ & Independent variable 2: CSR activities \\
\hline $\mathrm{X}_{3}$ & Independent variable 3: Transparency \\
\hline$\varepsilon$ & Random error (5\%) \\
\hline
\end{tabular}

The results of the regression were as follows:

Table 3. Linear regression test results

\begin{tabular}{lccccr}
\hline Variable & B & T-test & Sig & Lower Bound & Upper Bound \\
\hline Constant & 2.345 & 5.219 & .000 & 1.229 & 2.763 \\
\hline Communication & .257 & 1.405 & .725 & 3.162 & .382 \\
\hline CSR activities & .254 & 2.255 & .137 & 2.435 & .472 \\
\hline Transparency & .152 & 1.292 & .278 & -2.871 & .374 \\
\hline $\mathbf{R}$ & $44.1 \%$ & & & & \\
\hline $\mathbf{R}^{\mathbf{2}}$ & $45.3 \%$ & & & & \\
\hline $\mathbf{F}$ & 17.127 & & & \\
\hline Sig & $.000^{\mathrm{a}}$ & & & \\
\hline
\end{tabular}

To analyze the results of linear regression, we first look at the value of $\mathrm{F}$ and the constant Sig (Table 3). The table shows that both $\mathrm{F}$ and constant Sig have positive values. The second step examines the value of $\mathrm{R}$ and $\mathrm{R}^{2}$, which are in this case $44.1 \%$ and $45.3 \%$ respectively. These percentages are very high and reflect that the study is strong and valid where the relationship between the dependent and independent variables are positive.

When analyzing the results based on the upper and lower bound limits, it is observed that there is a positive value, which means that CSR communication as a measure of CSR has significant impact on managers' CSR awareness (reject $\mathrm{H}_{0 \mathrm{a}}$ ). 
Upon looking at the upper bound and lower bound for the second independent variable (CSR activities), we can see that CSR activities independent variable is positive which means that CSR activities as a measure of CSR has significant impact on managers' CSR awareness (reject $\mathrm{H}_{0 b}$ ).

As for the last independent variable, Transparency, we can see that the lower band value is negative. This suggests that there is no positive relationship between awareness and management transparency. It is important to point out that this may not be ultimately true while it indeed showed negative results, the sampled 88 top and middle level management officers of universities in Bahrain have not been exposed to situations where they felt that the management's transparency in CSR related matters have affected their awareness of the concept of CSR. In conclusion, the results presented above suggest that the Level of Management's Transparency as a measure of CSR has no significant impact on managers' CSR awareness.

\section{Conclusions, Recommendations and Limitations}

\subsection{Conclusion}

Based on the results of correlation and regression testing, it was found through this research that there is a significant relationship between communication and awareness of CSR in the management of universities from the tested sample.

On the other hand, it was shown that conducting CSR activities as a measure of CSR have a significant impact on managers' CSR awareness.

This was also supported by the finding that Nadeem and Kakakhel (2012) have when they stated that universities "need to concentrate more on stakeholders' concerns as they are the actors or entities who can influence universities directly or indirectly".

As for management's transparency, even though the study showed that it has no significance relationship between it and between awareness of CSR, it is still recommended that universities maintain transparency of the disseminated information regarding CSR as Kim and Ferguson (2014) stated that "corporations should make sure their message regarding CSR is less promotional and based on factual information. The information shared should be transparent without intentional omission of any negative information".

These findings does not necessarily mean that there is ultimately no relationship between management's transparency with the level of employee's awareness, it simply means that the tested sample of 88 respondents don't believe that this construct have a direct effect on their awareness of CSR.

\subsection{Limitations}

The intended population of the research was for all public and private universities in Bahrain. However, only few private universities accepted conducting the questionnaire of this research, the universities are with thanks: Ahlia University, AMA University, Kingdom University, University College of Bahrain, Arab Open University and Talal Abu Ghazala University College. The rejection from the other universities has led to a small sample of 88 respondents only. Another reason for having a relatively small sample is the fact that the targeted population of the research is top and middle level management who are usually busy and hard to approach.

\subsection{Recommendations}

Since the results showed that there is a positive relationship between conducting CSR activities and communication and the awareness of CSR in the management of universities, the researchers recommend that universities conduct more social activities to promote the concept of CSR among its managers and communicate it properly to the proper stakeholders. While the sample was enough to conduct the research, it would have been better to have a bigger sample to have a better idea on the implementation of CSR in the management of universities in the kingdom of Bahrain. For future researches, it is recommended to conduct a comparison between public and private higher educational institution in application of CSR. The researchers also recommend that managers get more training to enhance and improve their skills and knowledge of the concept of CSR and ways to use it to benefit their organizations.

\section{References}

Bahraincsrsociety.com. (2016). About BCSRS. Retrieved 1 May 2016, from http://www.bahraincsrsociety.com/about-bcsrs/

Giroud, X., \& Mueller, H. M. (2011). Corporate governance, product market competition, and equity prices. The Journal of Finance, 66(2), 563-600. https://doi.org/10.1111/j.1540-6261.2010.01642.x 
Jonson, E. P., McGuire, L. M., \& O’Neill, D. (2015). Teaching ethics to undergraduate business students in Australia: comparison of integrated and stand-alone approaches. Journal of Business Ethics, 132(2), 477-491. https://doi.org/10.1007/s10551-014-2330-5

Jorge, M. L., \& Peña, F. J. A. (2014). Determinants of corporate social responsibility and business ethics education in Spanish universities. Business Ethics: A European Review, 23(2), 139-153. https://doi.org/10.1111/beer.12041

Kim, S., \& Ferguson, M. T. (2014). Public expectations of CSR communication: What and how to communicate CSR. Public Relations Journal, 8(3), 1-22.

Mackey, A., Mackey, T. B., \& Barney, J. B. (2007). Corporate social responsibility and firm performance: Investor preferences and corporate strategies. Academy of Management Review, 32(3), 817-835. https://doi.org/10.5465/amr.2007.25275676

Mishra, S., \& Modi, S. (2016). Corporate Social Responsibility and Shareholder Wealth: The Role of Marketing Capability. Journal of Marketing, 80(1), 26-46. https://doi.org/10.1509/jm.15.0013

Nadeem, A., \& Kakakhel, S. J. (2012). An Investigation into Corporate Social Responsibility (CSR) of Public Sector Universities in KPK. Abasyn Journal of Social Sciences, 5(2), 14-27.

Nejati, M., Shafaei, A., Salamzadeh, Y., \& Daraei, M. (2011). Corporate social responsibility and universities: A study of top 10 world universities' websites.

Othman, R., \& Othman, R. (2012). Higher Education Institutions and Social Performance: Evidence From Public and Private Universities. International Journal of Business \& Society, 15(1), 1-18.

Topal R. Ş., \& Crowther, D. (2005). Social Responsibility, Quality and Academic Life. In D. Crowther, \& R. Jatana, (Eds.), International dimensions of corporate social responsibility (Vol. 1, pp. 97-118). Hyderabad: ICFAI University Press.

Vázquez, J. L., Lanero, A., \& Licandro, O. (2013). Corporate Social Responsibility and Higher Education: Uruguay $\begin{array}{llllll}\text { University Students'perceptions. } \quad \text { Economics } \quad \text { Sociology, } & 6(2),\end{array}$ https://doi.org/10.14254/2071-789X.2013/6-2/13 